\title{
Family history and recurrence of febrile seizures
}

A van Esch, E W Steyerberg, M Y Berger, M Offringa, G Derksen-Lubsen, J D F Habbema

\begin{abstract}
To determine the value of a detailed family history for the assessment of the risk of recurrence of febrile seizures, 115 children who visited the emergency room of an academic children's hospital were studied prospectively. The recurrence risk of febrile seizures was analysed in relation to the child's family history and the proportion of relatives affected by febrile seizures using Kaplan-Meier estimates and Cox proportional hazard models. A first degree family history positive for febrile seizures (parents or siblings affected by febrile seizures) increased a child's two year recurrence risk from 27 to $52 \%$. No significant increase of recurrence risk for febrile seizures was found in children with second degree relatives (grandparents and uncles/aunts) or cousins only affected by febrile seizures. Recurrence risk was significantly correlated with the proportion of first degree relatives affected by febrile seizures: risks were 27 , 40 , and $83 \%$ in children whose proportion was $0,0-0.5$, and $\geqslant 0.5$ respectively. Analysis of the recurrence risk in relation to a weighted proportion, adjusted for the attained age and sex of first degree relatives, showed similar results. It is concluded that the application of the proportion of first degree relatives affected by febrile seizures generates a more differentiated assessment of the recurrence risk of febrile seizures.

(Arch Dis Child 1994; 70: 395-399)
\end{abstract}

Pediatrics, Academic

Hospital

Rotterdam/Sophia

Children's Hospital,

The Netherlands

A van Esch

$M$ Offringa

G Derksen-Lubsen

Center for Clinical

Decision Sciences,

Department of Public

Health, Erasmus

University,

Rotterdam, The

Netherlands

A van Esch

E W Steyerberg

M Y Berger

$M$ Offringa

J D F Habbema

Correspondence to:

Dr Arjen van Esch, Cente for Clinical Decision Sciences, Department of Public Health, Room Ee2091, Erasmus University, Faculty of Medicine, Post Office Box 1738, 3000 DR Rotterdam, The

Netherlands.

Accepted 5 January 1994 in several studies; other risk factors are age at onset, multiple initial seizures, and relatively low temperature at the initial seizure..$^{4-7} 13$ The recurrence risks for febrile seizures have been reported in relation to the presence of first degree relatives (parents and siblings) affected by febrile seizures or in relation to the presence of affected relatives of any degree. ${ }^{31415}$ The predictive value of the presence of affected second and third degree relatives on the recurrence risk of febrile seizures is unknown. Also, the number of a child's relatives has not so far been taken into account. In general, a child's chance of having a family history positive for febrile seizures will be proportional to the number of relatives. Thus children with larger families will be more likely to have a positive family history. ${ }^{16}$ An incorporation of the number of relatives in the family history of febrile seizures may yield a more accurate assessment of a child's recurrence risk.

We investigated the association between the recurrence of febrile seizures and the presence of affected first degree relatives and the presence of affected second (grandparents, uncles/aunts) or third degree (cousins) relatives separately. We also investigated the recurrence of febrile seizures in children in relation to the proportion of first degree relatives affected.

\section{Patients and methods}

In an ongoing prospective clinic based follow up study 142 consecutive children with an initial febrile seizure at between 6 months and 6 years of age were included. They attended the emergency room of the Sophia Children's Hospital/Academic Hospital of Rotterdam between February 1988 and February 1990. Febrile seizures were defined in accordance with the National Institute of Health consensus statement. ${ }^{17}$ Fever had to be validated at home or in the hospital as a rectal temperature of $38.5^{\circ} \mathrm{C}$ or greater within a period of two hours before until two hours after seizure occurrence. A recurrence of febrile seizure was defined as a subsequent febrile seizure during a new febrile period. Age at onset, gender, parental country of origin, seizure type (duration, generalisation, multiplicity), temperature at onset, and first degree family history of febrile seizures were recorded on standard forms at the first visit. Children with remaining neurological damage or subsequent afebrile seizures (three children) and children given continuous prophylaxis (phenobarbitone or sodium valproate) for more than three months (14 children) were excluded, leaving a study group of 125 .

Parents were asked to report the recurrences of febrile seizures to the investigators. Recurrence histories were ascertained at follow up visits to the clinic by one of the authors (MO). Recurrence dates and characteristics

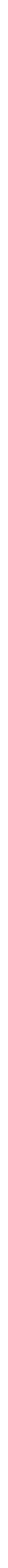


were recorded on standard forms. Subsequent to a mailed announcement two years after the initial febrile seizure, one investigator (AvE) contacted the parents by phone to obtain complete recurrence ascertainment. The parents of 10 children could not be contacted. Of the remaining 115 children, a detailed history of all first degree relatives (parents and siblings) - that is, birth date, sex, and seizure history (febrile or not, date, cause) - was obtained from the parents. In West European children a detailed history was also obtained of all second degree relatives (grandparents and uncles/aunts) and part of third degree relatives (cousins). In non-West European children a detailed history was obtained of all first degree relatives, but only of those second and third degree relatives who were affected by febrile seizures. Detailed family history data were recorded on standard forms. Seizures in relatives which occurred after the initial seizure of the index child were not taken into account. Where there was uncertainty about a relative's history, parents were asked to collect additional information and were contacted once more at a later date. Relatives whose febrile seizure history remained unknown were not taken into account in the analysis.

Two year cumulative risks of one and two recurrences of febrile seizures were estimated with Kaplan-Meier survival analysis. ${ }^{18}$ Univariate and multivariate Cox proportional hazard regression models were used to examine the effect of risk factors on the probability of subsequent febrile seizures. ${ }^{19}$ Hazard ratios with $95 \%$ confidence intervals (CIs) were computed to compare risks of different patient subgroups. The hazard ratio may be interpreted as a relative risk of recurrence.

Firstly, recurrence risks for febrile seizures were analysed in relation to the presence of first degree relatives affected by febrile seizures and in relation to the presence of affected second degree relatives or cousins. Differences

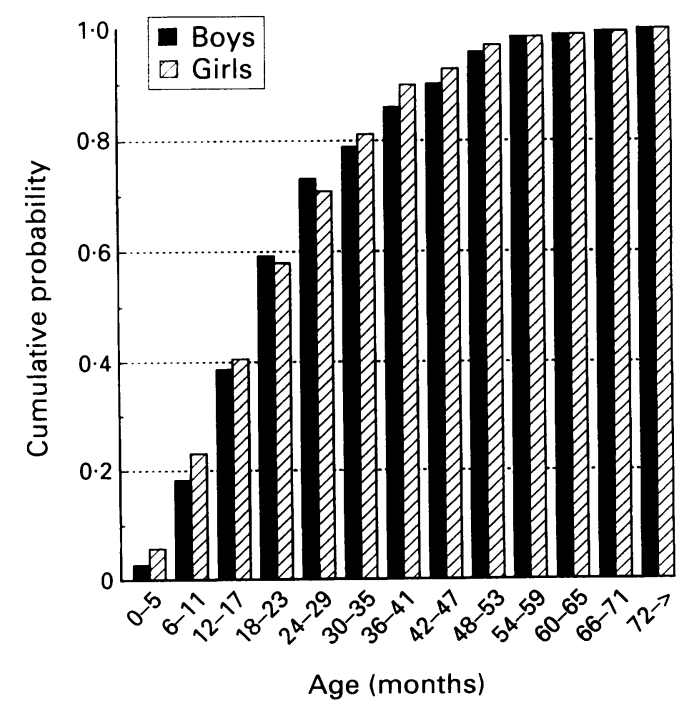

Figure 1 Cumulative probability of having a first febrile seizure before a certain age based on Offringa et al. ${ }^{1}$ The probability at 72 months is set at unity. The values are used as weights for relatives in relation to their gender and age. in the presence of relatives affected by febrile seizures between children were analysed with Pearson's $\chi^{2}$ test.

Secondly, recurrence risks were analysed in relation to the proportion of first degree relatives affected by febrile seizures, excluding the index child. This proportion was called the crude proportion of relatives affected by febrile seizures and can be expressed as

$$
\mathrm{N}_{\text {affected }} / \mathrm{N}_{\text {total }}
$$

For example, the crude proportion would be 0.33 if a child had one unaffected sibling and two parents, one of whom was affected.

Finally, risks were analysed in relation to a weighted proportion. This weighted proportion adjusts for the lower probability of a positive seizure history in young siblings. Weights for relatives were estimated from the cumulative probability distribution of age at onset in children with febrile seizures in a population based study ${ }^{1}$ (fig 1) - for example, a boy 20 months of age was assigned a weight of 0.59 . All parents and children of 6 years of age or older were assigned a weight of unity. The denominator of the weighted proportion constitutes the summated weights (W) of all first degree relatives ( $n$ ), whereas the numerator constitutes the number of positive relatives $\left(\mathrm{N}_{\text {affected }}\right)$, as it is in the crude proportion. Thus the weighted proportion of relatives affected by febrile seizures can be expressed as

$$
\mathrm{N}_{\text {affected }} / \Sigma \mathrm{W}_{\mathrm{i}} \quad(\mathrm{i}=1 . . \mathrm{n})
$$

A multivariate Cox proportional hazards model was used to examine the effect of family history, the crude proportion, and the weighted proportion of relatives affected by febrile seizures on the probability of the recurrence of febrile seizures, adjusting for other published risk factors for the recurrence of febrile seizures. ${ }^{4-7} 13$ These factors were age at onset (divided in three subgroups: $<1$, $1-2 \cdot 5$, and $>2 \cdot 5$ years), seizure type (simple or multiple), and temperature at the time of the first seizure (more or less than $40^{\circ} \mathrm{C}$ ). The effect of age on recurrence risk was analysed with the log rank test for trend.

\section{Results}

One hundred and fifteen children were included. Sixty five were of West European origin (mainly Dutch) and 50 were of nonWest European origin (mainly Mediterranean and Caribbean). The mean age at the first febrile seizure was 1.7 years. The median follow up of children without recurrences was $2 \cdot 1$ years; $81(70 \%)$ were followed for more than two years. Thirty six $(31 \%)$ children had one recurrence and 18 had two recurrences; the two year risks for one and two recurrences were 31 and $16 \%$ respectively (fig 2 ). Table 1 gives the clinical characteristics of the 115 children with the number, percentage, and hazard ratios of children with recurrences. Recurrence risks were significantly increased in children with multiple initial seizures (hazard 


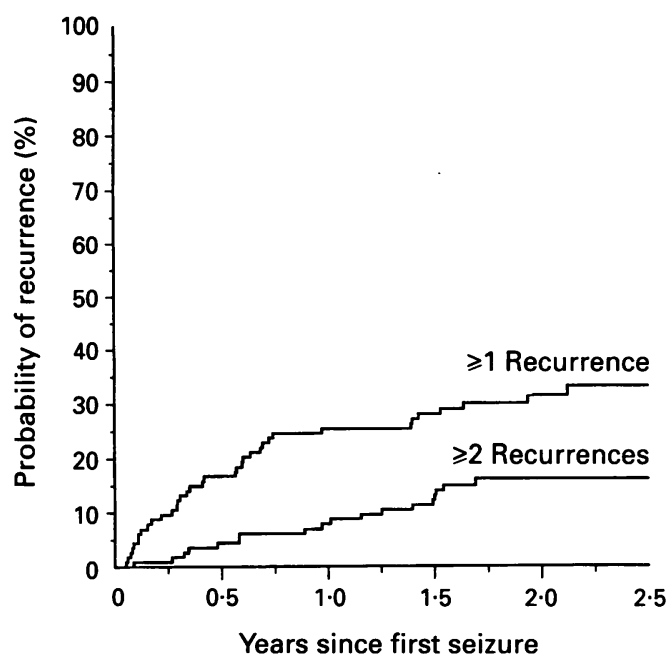

Figure 2 Probability of one and two recurrences after first febrile seizure

ratio $2 \cdot 3$ ), initial seizure durations of more than 15 minutes (hazard ratio $2 \cdot 3$ ), and a relatively low temperature at the initial seizure (hazard ratio $2 \cdot 1)$. Age at onset $(p=0 \cdot 07$, trend test), gender, and origin of parents had no significant effect on recurrence risk.

\section{FAMILY HISTORY OF FEBRILE SEIZURES}

A detailed febrile seizure history of 227 (total 230) parents and 121 (total 122) siblings could be obtained. Thirteen (6\%) parents and 12 $(10 \%)$ siblings had had a febrile seizure. Seventeen $(2 \cdot 8 \%)$ of 610 recorded second degree relatives and $12(2 \cdot 4 \%)$ of 493 recorded third degree relatives of children of West European origin had had a febrile seizure. In total, 24 second degree relatives and 20 cousins had had a febrile seizure.

Twenty one $(18 \%)$ children had affected first degree relatives (table 2). Twenty five $(22 \%)$ children had affected grandparents or uncles/aunts (second degree relatives) or cousins (part of third degree relatives). Risks of one and two recurrences in children with affected second degree relatives or cousins were similar to the risks of children without any affected relative. Risks of one recurrence in

Table 1 Recurrence risks in relation to clinical characteristics

\begin{tabular}{|c|c|c|c|}
\hline Feature & $\begin{array}{l}\text { No at risk } \\
(n=115)\end{array}$ & $\begin{array}{l}\text { No with seizure } \\
\left.\text { recurrence (risk } k^{\star}\right)\end{array}$ & $\begin{array}{l}\text { Hazard ratio } \\
\text { (CI)t }\end{array}$ \\
\hline \multicolumn{4}{|l|}{ Age at onset (years) } \\
\hline $\begin{array}{l}<1 \\
>2.5\end{array}$ & $\begin{array}{l}27 \\
72 \\
16\end{array}$ & $\begin{array}{r}11(41) \\
23(32) \\
2(13)\end{array}$ & $\begin{array}{l}1.4(0.7 \text { to } 2.8) \\
\text { rc } \\
0.4(0.1 \text { to } 1.5)\end{array}$ \\
\hline \multicolumn{4}{|l|}{ Gender } \\
\hline Male & 71 & $23(35)$ & $1 \cdot 1(0.5$ to $2 \cdot 1)$ \\
\hline Female & 44 & $13(27)$ & rc \\
\hline \multicolumn{4}{|l|}{ Origin of parents } \\
\hline West European & 65 & $18(27)$ & \\
\hline $\begin{array}{l}\text { Non-West European } \\
\text { Seizure type }\end{array}$ & 50 & $18(37)$ & $1.3(0.7$ to 2.5$)$ \\
\hline \multicolumn{4}{|l|}{ Seizure type } \\
\hline Multiple & 29 & $14(49)$ & $2 \cdot 3(1.2$ to 4.5$)$ \\
\hline Simple & 86 & $22(26)$ & rc \\
\hline Generalised & 108 & $34(32)$ & rc \\
\hline Focal & 7 & $2(29)$ & $0.9(0.2$ to 3.7$)$ \\
\hline$\geqslant 15$ minutes & 16 & $8(53)$ & $2.3(1.0$ to 5.0$)$ \\
\hline$<15$ minutes & 99 & $28(28)$ & rc \\
\hline \multicolumn{4}{|l|}{ Temperature at onset } \\
\hline$\geqslant 40^{\circ} \mathrm{C}$ & 59 & $13(23)$ & rc \\
\hline$<40^{\circ} \mathrm{C}$ & 56 & $23(41)$ & $2 \cdot 1(1 \cdot 1$ to $4 \cdot 1)$ \\
\hline
\end{tabular}

^Kaplan-Meier estimates (\%) of two year cumulative incidence.

fUnivariate hazard ratios with $95 \%$ CI compared with reference catagory (rc) children with affected first degree relatives, however, were significantly increased (univariate hazard ratio $2 \cdot 5$; multivariate hazard ratio $3 \cdot 2$ ). Risks of two recurrences showed a similar result (table 2 ).

Recurrence risks were studied in relation to the presence of affected parents or the presence of affected siblings separately. Table 3 shows that the recurrence risk was increased from 28 to $62 \%$ when the child had an affected parent (hazard ratio $3 \cdot 1$; CI 1.4 to $6 \cdot 7$ ). When a sibling affected by febrile seizures was present the recurrence risk was increased from 29 to $55 \%$ (hazard ratio $2 \cdot 4$; CI $1 \cdot 0$ to $5 \cdot 8$ ). Risks of two recurrences were increased from 14 to $31 \%$ (hazard ratio $2 \cdot 7$; CI 0.9 to $8 \cdot 1$ ) and from 15 to $27 \%$ (hazard ratio $2 \cdot 2$; CI 0.6 to $7 \cdot 7)$ respectively. Thus the presence of parents affected by febrile seizures and of siblings affected by febrile seizures had similar effects on the recurrence risk.

Recurrence risks of West European and non-West European children were studied separately because the percentage of children with first degree relatives affected by febrile seizures in non-West European children $(10 \%)$ was lower than in West European children $(25 \% ; p=0.04)$. In West European children recurrence risks were $19 \%$ in those without any affected first degree relatives and $50 \%$ in those with affected first degree relatives. In non-West European children, recurrence risks were 35 and $60 \%$ respectively. Univariate hazard ratios in children with affected first degree relatives were similar - that is, $2 \cdot 8$ (CI $1 \cdot 1$ to $7 \cdot 1$ ) in West European children and 3.3 (CI 0.9 to 11.6 ) in non-West European children.

CRUDE PROPORTION OF RELATIVES AFFECTED BY FEBRILE SEIZURES

Analysis of recurrences in relation to the crude proportion of affected relatives showed that the risk of one recurrence increased when the proportion increased (see fig 3 and table 4). The risk of two or more recurrences was only increased in children with a proportion greater than or equal to 0.5 (table 4 ), however. Univariate hazard ratios in this group were 6.3 for one and $5 \cdot 2$ for two recurrences respectively; multivariate hazard ratios were 6.8 and 5.7 .

\section{WEIGHTED PROPORTION OF RELATIVES}

AFFECTED BY FEBRILE SEIZURES

Finally, recurrence risks were analysed in relation to the weighted proportion of affected relatives, which is adjusted for the attained age and sex of the relatives (table 4). Although risks and hazard ratios were generally lower, the same pattern was observed as described in the crude proportion of relatives affected by febrile seizures.

\section{Discussion}

The aim of this study was to determine the value of a detailed family history for the prediction of the recurrence of febrile seizures. In 
Table 2 Number of recurrences of febrile seizures, risks and hazard ratios in relation to family history of febrile seizure

\begin{tabular}{|c|c|c|c|c|c|c|c|}
\hline \multirow{3}{*}{$\begin{array}{l}\text { Family history } \\
\text { of febrile seizures }\end{array}$} & \multirow{3}{*}{$\begin{array}{l}\text { No at } \\
\text { risk }\end{array}$} & \multicolumn{3}{|c|}{$\geqslant 1$ Recurrence } & \multicolumn{3}{|c|}{$\geqslant 2$ Recurrences } \\
\hline & & \multirow{2}{*}{$\begin{array}{l}\text { No } \\
\left(\text { risk }^{\star}\right)\end{array}$} & \multicolumn{2}{|c|}{ Hazard ratio $(\mathrm{CI}) \dagger$} & \multirow{2}{*}{$\begin{array}{l}\text { No } \\
\left(\text { risk }^{\star}\right)\end{array}$} & \multicolumn{2}{|c|}{ Hazard ratio $(C I) \dagger$} \\
\hline & & & Univariate & Multivariate & & Univariate & Multivariate \\
\hline $\begin{array}{l}\text { None } \\
\text { Second degree/cousins } \\
\text { First degree relatives } \\
\text { All }\end{array}$ & $\begin{array}{r}69 \\
25 \\
21 \\
115\end{array}$ & $\begin{array}{r}19(27) \\
6(24) \\
11(52) \\
36(31)\end{array}$ & $\begin{array}{l}\text { rc } \\
2 \cdot 5(1 \cdot 2 \text { to } 5 \cdot 1)\end{array}$ & $\begin{array}{l}\mathrm{rc} \\
3.2(1.6 \text { to } 6.6)\end{array}$ & $\begin{array}{r}10(15) \\
3(12) \\
5(23) \\
18(16)\end{array}$ & $\begin{array}{l}\text { rc } \\
2 \cdot 0(0.7 \text { to } 5.5)\end{array}$ & $\begin{array}{l}\text { rc } \\
2 \cdot 2(0 \cdot 7 \text { to } 5 \cdot 8)\end{array}$ \\
\hline
\end{tabular}

^Kaplan-Meier estimates (\%) of two year cumulative incidence.

†Hazard ratios with $95 \%$ CI compared with reference category (rc).

this prospective follow up study the recurrence risks were studied in relation to the presence of relatives affected by febrile seizures among first, second, and a part of third degree relatives, and in relation to the proportion of relatives affected by febrile seizures.

Detailed family history data were obtained through interviews by phone. This method has been shown to be almost as accurate as direct interviews. $^{20}$ Therefore we assume the accuracy of our interviews to be equivalent to that of a paediatrician's or general practitioner's interview. History data for febrile seizures of second degree relatives and cousins were obtained up to two years after the initial seizure in some children, possibly introducing some recall bias. In our experience, however, very little additional information on family history becomes available after seizure recurrences. Most family information is gathered by the parents after the occurrence of their child's initial seizure. Thus the accuracy of data on the history of febrile seizures in first degree relatives will only slightly differ between children with and without recurrences.

Previous studies have shown that $90 \%$ of children's first recurrences will occur within two years of the initial seizure. ${ }^{457}$ In this study $35(97 \%)$ of 36 children had their first recurrence within two years. Seventy per cent of the children without recurrences were followed for more than two years.

Overall risks of one and two recurrences in this study were $31 \%$ and $15 \%$ and are similar to recurrence risks in earlier studies. ${ }^{3-7}$ A twofold increase in the risk of one recurrence in children with a first degree relative affected by febrile seizures was also found in other studies. ${ }^{15-7}$

In previous prospective clinic based studies $25 \%$ of all children with a first febrile seizure had a first degree relative affected by febrile

Table 3 Recurrence risks in relation to febrile seizure history of relatives

\begin{tabular}{|c|c|c|c|}
\hline Feature & $\begin{array}{l}\text { No at risk } \\
(n=115)\end{array}$ & $\begin{array}{l}\text { No with } \\
\text { recurrence }\left(\text { risk }^{\star}\right)\end{array}$ & $\begin{array}{l}\text { Hazard ratio } \\
\text { (CI) } \dagger\end{array}$ \\
\hline \multicolumn{4}{|c|}{ No of siblings with febrile seizures } \\
\hline 0 & 103 & $30(29)$ & \\
\hline$\geqslant 1$ & 11 & $6(55)$ & $2 \cdot 4(1.0$ to $5 \cdot 8)$ \\
\hline \multicolumn{4}{|c|}{ No of parents with febrile seizures } \\
\hline 0 & 101 & $28(28)$ & rc \\
\hline 1 & 13 & $8(62)$ & $3 \cdot 1(1 \cdot 4$ to $6 \cdot 7)$ \\
\hline \multicolumn{4}{|c|}{ No of grandparents and uncles/aunts with febrile seizures } \\
\hline 0 & 96 & $31(32)$ & rc \\
\hline$\geqslant 1$ & 19 & $5(26)$ & $0.8(0.3$ to $2 \cdot 0)$ \\
\hline \multicolumn{4}{|c|}{ No of cousins with febrile seizures } \\
\hline 0 & 102 & $31(30)$ & rc \\
\hline$\geqslant 1$ & 13 & $5(38)$ & $1.4(0.5$ to 3.5$)$ \\
\hline
\end{tabular}

^Kaplan-Meier estimates (\%) of two year cumulative incidence.

tUnivariate hazard ratios with $95 \%$ CI compared with reference category (rc). seizures. ${ }^{621}$ In this study affected first degree relatives were present in $18 \%$ of cases. The percentage of children with affected first degree relatives in non-West European children $(10 \%)$ was significantly lower than the percentage in West European children $(25 \%)$. There is no reason to assume a lower incidence of febrile seizures in Mediterranean or Caribbean children than in West European children. More likely there has been underreporting of affected first degree relatives, possibly caused by reluctance to reveal the occurrence of febrile seizures to the investigator or by hampered access to parents living abroad. The presence of affected first degree relatives yielded similar recurrence hazards in West European and in non-West European children, which is indicative of non-selective underreporting of relatives affected by febrile seizures.

No significant increase in febrile seizure recurrence was found in children with affected second degree relatives or cousins only; the history of febrile seizures in second degree relatives and cousins therefore appears to have little value in estimating a child's risk of recurrence.

The crude proportion of affected relatives that is, the proportion of first degree relatives affected by febrile seizures - yielded much more discrimination of recurrence risks of febrile seizures than common family history of febrile seizures. With the use of this crude proportion children with a sixfold increased risk of one and fivefold increased risk of two recurrences could be identified - that is, those children of whom $50 \%$ or more of the first degree relatives were affected. Risks of

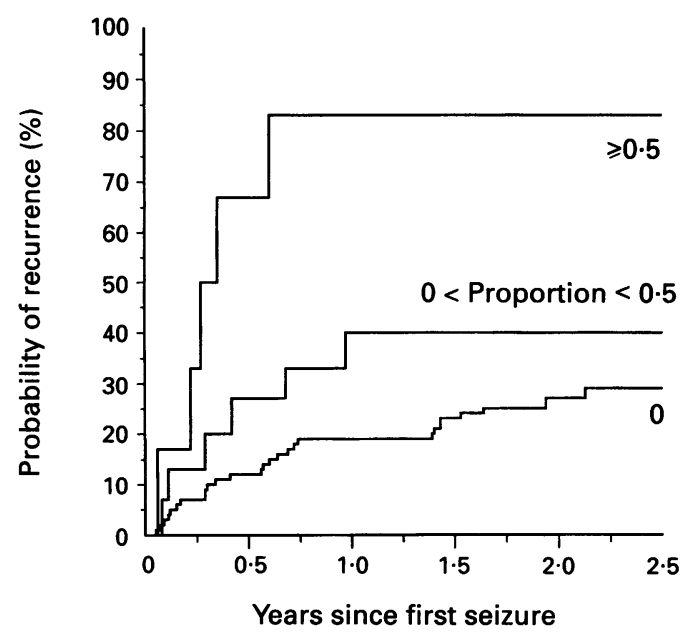

Figure 3 Probability of recurrence in relation to the proportion of relatives affected by febrile seizures. 
Table 4 Recurrences risks for febrile seizures according to the crude proportion and the weighted proportion of first degree relatives affected by febrile seizures

\begin{tabular}{|c|c|c|c|c|c|c|c|}
\hline \multirow[b]{3}{*}{ Proportion } & \multirow{3}{*}{$\begin{array}{l}\text { No at } \\
\text { risk }\end{array}$} & \multicolumn{3}{|c|}{$\geqslant 1$ Recurrence } & \multicolumn{3}{|c|}{$\geqslant 2$ Recurrences } \\
\hline & & \multirow{2}{*}{$\begin{array}{l}\text { No } \\
\left(\text { risk }^{\star}\right)\end{array}$} & \multicolumn{2}{|l|}{ Hazard ratio $(C I) \dagger$} & \multirow{2}{*}{$\begin{array}{l}\text { No } \\
\left(\text { risk }^{\star}\right)\end{array}$} & \multicolumn{2}{|l|}{ Hazard ratio $(C I) \dagger$} \\
\hline & & & Univariate & Multivariate & & Univariate & Multivariate \\
\hline \multicolumn{8}{|l|}{ Crude proportion } \\
\hline 0 & 94 & $25(27)$ & $\mathrm{rc}$ & $\mathrm{rc}$ & $13(14)$ & & \\
\hline $0<$ proportion $<0.5$ & 15 & $6(40)$ & $1 \cdot 7(0 \cdot 7$ to $4 \cdot 1)$ & $2 \cdot 2(0.9$ to 5.6$)$ & $2(13)$ & rc & rc \\
\hline$\geqslant 0.5$ & 6 & $5(83)$ & $6 \cdot 3(2 \cdot 4$ to $16 \cdot 8)$ & $6.8(2.4$ to $19 \cdot 1)$ & $3(50)$ & $5.2(1.5$ to 18.3$)$ & $5.7(1.4$ to 18.5$)$ \\
\hline \multicolumn{8}{|l|}{ Weighted proportion } \\
\hline 0 & 94 & $25(27)$ & rc & rc & $13(14)$ & & \\
\hline $0<$ proportion $<0.5$ & 13 & $5(38)$ & $1.7(0.6$ to 4.4$)$ & $2 \cdot 2(0.8$ to $6 \cdot 1)$ & $2(15)$ & rc & rc \\
\hline$\geqslant 0.5$ & 8 & $6(75)$ & $4.4(1.8$ to 10.8$)$ & $5 \cdot 1(2 \cdot 0$ to $12 \cdot 8)$ & $3(47)$ & $3.4(1.0$ to 11.8$)$ & $3.5(1.0$ to 12.5$)$ \\
\hline All & 115 & $36(31)$ & & & $18(16)$ & & \\
\hline
\end{tabular}

*Kaplan-Meier estimates (\%) of two year cumulative incidence.

tHazard ratios with $95 \%$ CI compared with reference category (rc).

two recurrences in these children were also significantly increased.

Although expected in theory, no improvement in the risk assessment of the recurrence of febrile seizures was achieved by use of the weighted proportion of affected relatives, with adjustment for the attained age and sex of the relatives. This may be due to the fact that two thirds ( 227 of 348 ) of first degree relatives were parents. Thus most relatives were no longer at risk of a febrile seizure at the initial seizure of the index children.

Both genetic and environmental mechanisms have been suggested for the susceptibility to an increased risk of the recurrence of febrile seizures. ${ }^{51522-25}$ In our study recurrence risk for febrile seizures in children with affected siblings were similar to recurrence risks in children with affected parents. These findings support a mainly genetic mechanism because environmental risk factors would have induced a larger effect on the recurrence risk of siblings than of parents affected by febrile seizures. An autosomal dominant mode of transmission can be assumed in children with proportion values of 0.5 or more. Rich et al postulated an autosomal dominant mode of inheritance in children with frequent recurrences. ${ }^{26}$

We conclude that a first degree family history is of major importance in the assessment of the recurrence risk for febrile seizures; second and third degree family histories appear to be of minor importance. The proportion of affected first degree relatives yields the highest differentiation of the recurrence risk for febrile seizures. This proportion of relatives affected by febrile seizures may prove a useful tool to assess the recurrence risk of febrile seizures in daily paediatric practice because of the simple assessment and the uncomplicated calculation of the proportion.

The authors thank C $M$ van Duijn, $\mathrm{PhD}$ for her helpful comments.

1 Offringa M, Hazebroek AAJM, Derksen-Lubsen G. Prevalence of febrile seizures in Dutch schoolchildren. Paediatr Perinatol Epidemiol 1991; 5: 181-8.
2 Forsgren L, Sidenvall R, Blomquist HK, Heijbel J. A prospective incidence study of febrile convulsions. Acta Paediatr Scand 1990; 79: 550-7.

3 Verity CM, Butler NR, Golding J. Febrile convulsions in a national cohort followed up from birth. I: Prevalence and recurrence in the first year of life. $B M F$ 1985; 290: 1307-10.

4 Nelson K.B, Ellenberg JH. Prognosis in children with febrile seizures. Pediatrics 1978; 61: 720-7.

5 Offringa M, Derksen-Lubsen G, Bossuyt PM, Lubsen J. Seizure recurrence after a first febrile seizure: a multivariate approach. Dev Med Child Neurol 1992; 34: 15-24.

6 Knudsen FU. Recurrence risk after first febrile seizure and affect of short term diazepam prophylaxis. Arch Dis Child 1985; 60: 1045-9.

7 Annegers JF, Blakley SA, Hauser WA, Kurland LT Recurrence of febrile convulsions in a population-based cohort. Epilepsy Res 1990; 5: 209-16.

8 Farwell JR, Lee YJ, Hirtz DG, Sulzbacher SI, Ellenberg JH, Nelson KB. Phenobarbital for febrile seizures - effects on intelligence and on seizure recurrence. $N$ Engl $\mathcal{f} \mathrm{Med}$ 1990; 332: 364-9.

9 Chessare JB, Berwick DM. Variation in clinical practice in the management of febrile seizures. Pediatr Emerg Care 1985; 1: 19-21.

10 Knudsen FU. Effective short-term prophylaxis in febrile convulsions. F Pediatr 1985; 106: 487-90.

11 Autret E, Billard C, Bertrand P, Motte J, Pouplard F, Jonville AP. Double-blind, randomized trial of diazepam versus placebo for prevention of recurrence of febrile seizures. F Pediatr 1990; 117: 490-4.

12 Rosman NP, Colton T, Labazzo J, et al. A controlled trial of diazepam administered during febrile illnesses to prevent recurrence of febrile seizures. N Engl f Med 1993; 329: 79-84.

13 El Rhadi AS, Banajeh S. Effect of fever on recurrence rate of febrile convulsions. Arch Dis Child 1989; 64: 869-70.

14 Wolf SM, Carr A, Davis DC, et al. The value of phenobarbital in the child who has had a single febrile seizure: a controlled prospective study. Pediatrics 1977; 59: 378-85.

15 Frantzen E, Lennox-Burchthal M, Nyaard A, et al. A genetic study of febrile convulsions. Neurology 1970; 20: 909-17.

16 Bethune P, Gordon K, Dooley J, et al. Which child will have a febrile seizure? Am $\mathcal{F}$ Dis Child 1993; 47: 35-9.

17 Millichap JG. The definition of febrile seizures. In: Febrile seizures. New York: Raven Press, 1981: 2.

18 Kaplan EL, Meier P. Nonparametric estimates from incomplete observations. Fournal of the American Statistical plete observations. fournal of
Association 1958; 53: 457-81.

19 Cox DR. Regression models and life-tables. Fournal of the Royal Statistical Society [B] 1972; 34: 187-220.

20 Tausig TE, Ellen MSW, Freeman W. The next best thing to being there: conducting the clinical research interview by telephone. Am f Orthopsychiatry 1988; 58: 418-27.

21 Berg AT, Shinnar S, Hauser WA, et al. A prospective study of recurrent febrile seizures. $N$ Engl f Med 1992; 16: 1122-7.

22 Baraitser M. Relevance of a family history of seizures. Arch Dis Child 1983; 58: 404-5.

23 Tsuboi T. Genetic aspects of febrile convulsions. Hum Genet 1977; 38: 169-73.

24 Hauser WA, Annegers JF, Anderson VE, Kurland LT. The risk of seizure disorders among relatives with febrile conrisk of seizure disorders among relatives
vulsions. Neurology 1985; 35: 1268-73.

25 Forsgren L, Sidenvall R, Blomquist HK, Heijbel J, Nystrom L. An incident case-referent study of febrile convulsions in children: genetical and social aspects. Neuropediatrics 1989; 21: 153-9.

26 Rich SS, Annegers JF, Hauser WA, Anderson VE. Complex segregation analysis of febrile convulsions. Am Hum Genet 1987; 41: 249-57. 